\title{
Islam, national identity and public secondary education: perspectives from the Somali diaspora in Toronto, Canada
}

\author{
Bruce A. Collet* \\ York University, Toronto, Canada
}

\begin{abstract}
Public schools have historically been key sites where children learn of and adopt a common national identity. In states where multicultural ism plays a central role in the articulation of a national identity, schools actively recognize and support the diverse cultures of their students in fulfilling this function. Canada is a state where, via federal policy, multiculturalism has been identified as a fundamental element of the national ethos. Formal education has been a key area in which the government has implemented this policy. However, public education in Canada is also committed to secularism, and this has been a cause for resistance by diverse immigrant groups. This paper examines resistance among traditional Muslim groups to Toronto school policies and practices that reflect an avowedly secular orientation. It focuses on the experiences of one Muslim group in particular, Somali immigrants, and their encounters with school policies and practices that both supported and challenged their identities. In doing so, the paper exposes the schools as sites of countervailing policies and practices within which students must nonetheless forge new and meaningful identities.
\end{abstract}

\section{Introduction}

Public schools have historically been key sites where children learn of and adopt a common national identity. In states where multiculturalism plays a central role in their national identities, schools actively recognize and support the diverse cultures of their students in fulfilling this function. Canada is a state where, via federal policy, multiculturalism has been identified as a fundamental element of the national ethos. Yet Canada remains far from being resolved in terms of what multiculturalism actually looks like in practice. This is reflected in its public school policies and practices, which reflect both multicultural as well as orthodox liberal orientations.

In this article, I examine resistance among traditional Muslim groups to Toronto school policies and practices that reflect an overtly secular orientation. I then move

*91 Fortieth Street, Toronto, ON, Canada M8W 3N2. Email: bcollet@yorku.ca. Bruce Collet will be joining the College of Education and Human Development at Bowling Green State University in August 2007. 
on to look at the school experiences of one unique group of students in Canada: Somali immigrants. Based on interviews conducted with 30 Somalis who graduated from Ontario public high schools, the piece explores the students' experiences with school policies and practices that both supported and challenged their identities. The research presented here examines what these experiences might indicate about the relationship between the schools and the diverse populations that they serve. More so, it uses the school as a window through which to look at the processes that Somali students engage in as they create new and meaningful identities for themselves.

\section{Method}

This article draws from data I collected for a study on the relationship between the migration experiences of Somali immigrants and refugees, their participation in secondary schools in the Ontario public school system, and their perceptions of a national identity. The study is based on semi-structured interviews I conducted with 33 young Somali adults in Toronto between July and December 2004. All of the young people who participated in the study had graduated from an Ontario public high school within five years of the interview (and many in fewer years than that). Sampling for the study was purposeful, utilizing both concept- and network-based sampling. Two Toronto-based community agencies, Midaynta Community Services and the Somali-Canadian Working Group for New Generation, agreed to be cooperating institutions for the recruitment of interviewees. ${ }^{1}$

Study participants were divided evenly between men and women. Just over half of the interviewees had come to Canada during the middle years of their childhoods (7-12 years old), while the remaining had migrated during their teen years or early twenties. There were a total of 17 different high schools represented in the sample. ${ }^{2}$ While there was some variety regarding the types of high schools that the interviewees attended, all of the schools adhere to the Ontario Ministry of Education curriculum, which is one of the primary forces of cohesion across the interviewee educational experiences. ${ }^{3}$

The interview schedule used in the study was divided into four main sections. Part one addressed pre-migration identification categories, while part two concerned experiences of transition to Canada. Part three concentrated on schooling in Ontario and identity processes, while the final section concentrated on present identification categories. I employed Boyatzis' (1998) data-driven approach to the development of themes and codes for analysis. Inter-rater review was used to determine the reliability of codes. It is important to recognize here the advantages and disadvantages of this type of interpretive biography. On the one hand, the study benefited greatly from using an inductive method of thematic analysis in that it relied on first-person accounts and employed 'grounded' perspectives. However, there are certain limitations related to conducting research as an 'outsider' (i.e. a non-Somali) as well as interviewing students about their schooling after they have graduated. Both of these conditions may have increased the possibility of 'selective memory' on the part of the 
interviewees, and thus the data must be viewed within the context within which they were gathered.

\section{Schooling, and the construction of a national identity in the Canadian context}

Political socialization as defined by Richard Braungart and Margaret Braungart is the process of learning political attitudes and behavior through social interaction (Braungart \& Braungart, 1997). Erwin Epstein and Noel McGinn expand this definition to assert that political socialization involves socialization into a culture that supports a particular political structure (Epstein \& McGinn, 2000). Schools are regarded as the principal social institutions in society formally charged with engaging children in this process. Here schools aim to create a common understanding of national and patriotic identity in terms of what are imagined by the state to be legitimate expressions (Waters \& Leblanc, 2005). In this most basic understanding of political socialization and education, it is by means of schools that younger generations learn about political philosophy, citizenship and the core ideology of the society in which they live. Because childhood and adolescence are formative stages for developing social and political orientations, most of the focus on political socialization across national contexts occurs in primary and secondary school systems (Braungart \& Braungart, 1997).

Yet the processes by which young people actually acquire political attitudes and a sense of political identity and citizenship, as well as the real role that schools play in engaging students in these processes, are far more complex than what the term 'political socialization' might convey on its own. Indeed, the term itself carries implicit assumptions regarding how students go about acquiring certain attitudes and behaviors. Likewise, the very notion of 'formally charging' a school with the role of teaching certain political attitudes and behaviors, and assuming that schools play direct and primary roles in this process carries assumptions about how education and the learning of political behavior work together. Are students simply receivers of political knowledge and orientations that fall in line with the core ideology of the society in which they live, or do they play more constructive and possibly contesting roles in this process? As will be demonstrated further in this article, the case of Somali students in the Toronto public schools presents a very interesting set of challenges to the manner in which schooling and the construction of identity has been traditionally conceptualized.

The advent of Pierre Trudeau's official state policy of multiculturalism in 1971, while arguably benevolent in its intentions, opened a Pandora's box in Canadian society, as competing notions of what constitutes a national identity within an increasingly pluralistic society have come to the fore. In fact, the very definition and meaning of a Canadian national identity has been depicted by some Canadian scholars as being in a state of crisis (Rosa \& Dick, 2000). While this is certainly not uniformly believed, it is an area of ideological contention that has important implications for newcomers to the school system. 
To unravel the circumstances and conditions that have led to this current state of affairs, it is helpful to examine some key time periods in Canadian history during which national identity was of central concern. The first involves the British and French cultural tapestry and historical roots, as well as the assimilationist policies of the provincial and federal governments between 1867 and 1945. The second concerns important cultural transitions that occurred in the country during World War II and the years immediately following it. The third concerns the 1960s and early 1970s, which witnessed the formal adoption of a federal policy of multiculturalism. Finally, the fourth period of significance flows from the adoption of multiculturalism as an official state policy to the present period.

From the birth of Canada as a nation state in 1867, the country's immigration policies, and indeed the Canadian national ethos, was by and large driven by Angloconformity in the English-speaking provinces and French cultural preservation in Quebec. Howard Palmer (1993) writes in fact that one of the most important objectives of the 1867 Canadian confederation was the accommodation of British and French cultures. The overall mission of public education in Canada during this period was to instill patriotism in Canadian youth, which, in all provinces except Quebec, meant learning to be a good Canadian citizen in the image of British loyalists (Joshee, 2003). Schools were thus by and large homogenizing forces in society, working to assimilate as quickly as possible various ethnicities into the Anglo culture. ${ }^{4}$ In the case of Quebec, most French Canadians were more preoccupied with the defense of their own status than they were in assimilating non-French groups into their society, a task they did not have to concern themselves with much, as relatively few non-French immigrants went to Quebec (Palmer, 1993).

World War II and the postwar years proved to be a transitional time for Canada with respect to attitudes toward immigration and ethnicity, as a changing intellectual and social climate diminished nativism and prejudice (Palmer, 1993). During the war, the federal government in Canada had an acute interest in ensuring that all Canadians, regardless of their origin, supported the war effort. The particular ethnic and racial dynamics of the war had special significance for the emerging national ethos, as Canadian wartime propaganda fronted the country as tolerant of diversity and difference, in contrast to the intolerance of the German Third Reich. The federal government made specific steps during this time to reach out to various ethnic groups, including the establishment of ethno-cultural organizations, and the passage of the 1947 Citizenship Act, which witnessed the creation of a Canadian passport (Joshee, 2003).

It was not until the 1960s, however, that pressures for ethnic tolerance and a growing realization of structural inequalities between immigrant groups began to create an environment conducive to a deeper pluralistic orientation on the part of the government. This orientation would finally make its way into federal policy in 1971 with the implementation of a national policy of multiculturalism.

While, ostensibly, multiculturalism appears geared toward making Canada a more open and accepting society, the exact political motives and history are important to tell. Multiculturalism in Canada is more accurately known as multiculturalism 
'within a bilingual framework'. The bilingual component of the policy stems from the earlier work of a Royal Commission to secure the status of the French language in Canada, a reflection of larger efforts on the part of French Canadians to secure the status of their culture and identity (Palmer, 1993). It is likely that a bicultural as opposed to multicultural policy would have evolved from the Commission's work, had it not been for sentiments expressed by other ethnic groups at the time that their distinct cultures and identities might be relegated to a second-class status owing to the exclusive emphasis on French and English cultures. Trudeau's 1971 policy is thus one of accommodation to pressures from diverse ethnic constituencies, and in fact has been depicted as an 'ironic mistake' by some writers (Mazurek \& Kach, 1990).

The history behind Canada's multicultural orientation hints at vestiges of an earlier Canada, a country focused specifically on its Euro roots, and one with which a great number of Canadians still identify. Nonetheless, since the early 1970s it has been Canada's policy of multiculturalism, and its identification as a liberal democratic state, that has perhaps most influenced secondary school curricula with regard to national identity (Froese, 2003).

Formal education has been a key area within which the government has implemented its policy of multiculturalism, despite the fact that there exists no federal department of education. This is because the government maintains involvement in areas deemed to be in the national interest. Public education in Canada is formally a provincial responsibility, and each of the country's 10 provinces and 3 territories have their own ministries or departments of education. Policies stemming from these departments are in turn implemented within the purview of local and regional school districts. Beginning in the early 1970 s, the federal government used a number of strategies to move multicultural initiatives forward across the districts. One of the largest of these strategies was its Cultural Enrichment Program, which had as its explicit goal the learning and retention of heritage languages. While it is true that this program was dismantled in the early 1990s, and that generally similar government efforts began to wane by the $1990 \mathrm{~s}$, multiculturalism still plays a significant role in Canadian education (Joshee, 2003).

Despite considerable variation in the implementation of multiculturalism through schools across Canada, Kas Mazurek and Nick Kach nonetheless identify two areas of clear consensus. The first is that multiculturalism is important and to be taken seriously. The second is that the ideology of multiculturalism is to permeate virtually the entirety of educational theory, practice and administration (Mazurek \& Kach, 1990).

There is a second equally important dimension to national identity and education in secondary school practices in Ontario, and this concerns democratic citizenship. As a parliamentary democracy, the Canadian government has a vested interest in fostering an informed and active democratic citizenry. This interest is reflected in educational mandates. Yvonne Hebert, for example, writes that schools in Canada have been historically called upon to produce a citizenry strongly bonded to the state and its interests (Hebert, 2001). Recalling Epstein and McGinn's assertions regarding democratization and national identity, the cultivation of civic identification within a democracy further entails possessing a consciousness of one's condition within the 
state, and the uniqueness of democratic life including an understanding of democratic concepts and an activation of democratic values.

To the extent that the above calls for a Canadian civic identity entail transcending attention and sensitivity to particular cultures, they reflect a position more in line with orthodox liberalism (May, 1999). Proponents of orthodox liberalism argue that the politics of multiculturalism are inherently destabilizing and destructive of the bonds of nationhood. ${ }^{5}$ Multiculturalism in their view replaces universalism with particularlism, and introduces ethnicity unnecessarily and unproductively into the civic sphere, a realm that in fact should be kept neutral to ensure personal autonomy, equality and common citizenship (May, 1999).

Multiculturalists counter orthodox liberals first and foremost by questioning the apparent 'neutrality' of the civic realm, arguing that any common identity springing from such is in fact a disguise for the dominance of one cultural group over others. Multiculturalists hold that the public is in fact cultural by nature, and that the public sphere is an arena for cultural negotiation, where the ultimate goal is cultural inclusion. Multiculturalists thus encourage the growth of cultural particularlism as a means toward strengthening a multicultural national identity (Feinberg, 1998).

As the debate is played out in education, orthodox liberals view the role of public schools as striving to unify all children, regardless of their cultural affiliation, under a single national identity. While they may state that schools do have a role of teaching children to respect cultural difference in general, they steadfastly maintain that it is not the place of schools to advance a child's particular cultural identity. Multiculturalists approach education from nearly an opposite philosophical orientation. In contrast to orthodox liberals, they see the role of public schools as actively recognizing the cultural identities of its student body, and addressing the children not just as citizens of one nation, but in terms of their identity as members of different cultural groups. Hence it is, according to multiculturalists, precisely the role of schools to establish respect for cultural variation and to promote pride in one's cultural heritage (Feinberg, 1998). In the Canadian context, and particularly in Ontario, the above dualism manifests itself in countervailing school policies and practices, as made evident in the following section regarding Muslims and the Toronto public schools.

\section{Muslims and the public school system in Toronto}

The Muslim encounter with the public school system in Toronto presents an opportunity to view the manner in which the particular belief systems of immigrant and refugee communities have invited a critical look at the parameters of multiculturalism, as well as exposed the depth to which the schools have remained well-entrenched within liberal secular orientations. Resistance among traditional Muslim groups to several important elements of public education in Canada also reveals paradoxical school policies and practices that reflect multicultural as well as orthodox liberal positions.

In a study of Muslim educational institutions in Toronto, Shaheen Azmi (2001) states that there has been a fairly long history of Muslim community discontent with 
the public schools. ${ }^{6}$ During the 1960 s and the 1970 s, nearly all Muslim children in the Greater Toronto Area (GTA) attended public schools. In the 1970s, a spirited effort emerged from within the Muslim community to address what were perceived to be anti-Muslim and anti-Islamic biases in the school textbooks. The movement to change the curriculum was only partially successful in meeting its goals, and, according to Azmi, 'confirmed that there existed only a token willingness to accommodate Muslim concerns on the part of education authorities' (Azmi, 2001, p. 262).

The struggle between traditional Muslim groups and the Toronto public schools continued up through the 1990s. In 1992, a public school filed a report to the Toronto Board of Education stating that Muslim parents were not allowing their children to participate in several school activities, including swimming, dancing and music for religious reasons. The Board's response was to establish a Cultural and Religious Practices Group with the support of the Equal Opportunity Office and the Equity Studies Centre. The group, made up of school staff and Muslim parents and religious leaders, produced a document entitled Report on the religious needs of Muslim students in the Toronto Board of Education (Toronto Board of Education, 1992). The report identified several Muslim concerns regarding extant public school practices, including gender-integrated physical education, the health and sexuality education curriculum and select components of the arts curriculum. The report also addressed the need for accommodations for Muslim daily and Friday prayers, as well as fasting during the month of Ramadan. In the report, the group offered potential solutions that it deemed to be in line with overall board policy. Later in 1999, members of the Muslim community spearheaded a major protest against a new policy implemented by the Toronto District School Board that moved to include the coverage of sexual orientation in the health and sexuality curriculum (Azmi, 2001).

Responses from the Board to these multiple grievances have varied. With regard to the provisions required for daily and Friday prayers, beginning in the early 1990s several Toronto schools began to set aside space within their facilities to make this possible. Later, such special accommodations became official policy across the Toronto schools (The Report, December 1, 2001). Responses to the other grievances were much more thorny and complex. For example, with regard to the Cultural and Religious Practices Group 1992 report, the Board stated that it could with some exceptions find ways to accommodate the stated concerns. The exceptions revolved around those concerns that ran contrary to the avowedly secular liberal character of public education in Ontario. Azmi writes that these 'exceptions' clearly related to Muslims 'who identify themselves more thoroughly with the Islamic tradition' (Azmi, 2001, p. 263).

The exceptions of particular interest here include physical education and instruction pertaining to sex and sexuality. Physical education classes in the Toronto Public Schools include both same-sex and mixed-sex classes. Further, the Ontario Ministry of Education and the Toronto Public Schools have maintained in their curriculum pertaining to healthy growth and sexuality instruction on the effectiveness of varying methods of birth control, as well as the prevention of sexually transmitted diseases (Ontario Ministry of Education, 1999). As noted above, traditional Muslim groups 
have raised issues regarding gender-integrated physical education in the Toronto schools. As well, the groups have remained steadfastly opposed to sex education in the public schools, both on the grounds of content and on the fact that it is carried out in a public space (McGown, 1999). ${ }^{7}$

As mentioned, the nature of the Toronto District School Board responses to traditional Muslim concerns reflect seemingly countervailing school policies and practices. The acquiescent measures and later official policy of providing space to allow for Muslim daily and Friday prayers undoubtedly reflects the Board's commitment to multiculturalism. Here, the schools have actively recognized the cultural identities of Muslim students, and have in this way opened the schools as sites for supporting these identities. ${ }^{8}$ Yet, at the same time, the Board's commitment to secularism, made explicitly in its policies regarding gender integrated physical education and the curriculum on healthy growth and sexuality, reflects a position much more in line with orthodox liberalism. Here, the schools have embraced a curriculum that transcends the cultural particularlism associated with multiculturalism.

Thus, in Toronto, the educational contexts within which Muslim students construct their identities are volatile sites, wherein there exist seemingly countervailing school policies and practices. These policies and practices reflect a continuing struggle not only between traditional cultural groups and the schools, but also, as a result of these struggles, within the schools themselves between multicultural and liberal secular orientations. Yet a real gauge to employ in assessing how these potentially contradictory environments interrelate with student identity constructions is to ask the students themselves. It is with this in mind that I now turn to looking at one population of Muslim students in particular-Somali immigrants.

\section{Somalis in Toronto, and Islam as a significant identity marker}

Toronto, Ontario, has been one of the largest settlement destinations of Somali immigrants and refugees in the northern hemisphere (Kusow, 1998). Estimates of the actual size of the community vary. In 2000, Toronto's Globe and Mail put the figure between 40,000 and 50,000 (Immen, 2000). However, Toronto community agencies that serve Somalis such as Midaynta Community Service estimate a much larger number of 80,000-100,000 (Midaynta Association of Somali Service Agencies, 2003). ${ }^{9}$ Compared with other immigrant communities in Toronto, the Somalis are quite new, as more than $80 \%$ have been in the city only since 1988 . With regard to the cultural impact of Somalis in Toronto, Azmi notes that the sizable influx of Somali immigrants who came into the GTA during the 1980 s and 1990 s added significantly to the region's overall Muslim population (Azmi, 2001).

Islam has a long and important history in Somalia, and has impacted the identity of its people profoundly. While it is beyond the scope of this article to delve into this history in detail, an overview of the relationship provides some context. Virtually all Somalis are Muslims, and are strongly attached to this identity (McGown, 1999). Scholarship indicates that the presence of Islam in the country dates to AD 622, or from the first century after the hijra. ${ }^{10}$ The religion spread gradually from the north 
into the interior over a period of centuries, aided by trade routes, a short-lived Islamic state in the south, a confederacy of clans closely associated with Islam, and a sixteenth-century jihad against Christian Ethiopia (McGown, 1999).

In tracing the Islamization of Somalia, it is important to note that the process has involved the overlay of Islam on traditional customs and beliefs, which in turn has affected how Islam is lived on a day-to-day basis. Thus, for example, in the rural areas, Somalis have relied more on traditional customs (xeer or heer) than on the shari'a (Islamic religious laws) in regulating their lives. Further, given Somalia's history as primarily an oral culture, creation myths concerning Arabic lineages have enjoyed much currency in the country. Here, the ability to trace one's family back directly to an Arab ancestor grants considerable prestige within Somali society. Not surprisingly, traditional ancestor cults have used such currencies to distinguish themselves from those not thought able to claim such pasts, resulting in deep social divisions within the society.

In contemporary Somalia, there exist three separate Islamic orders (or Tariqas): the Qadiriya, the Ahmadiya and the Salihiya. Abdi Kusow (1998) asserts that, despite the fact that Islam serves as a unifying force for a joint perception of Somalihood, there are at times intense competitions between these orders. While clans will not be discussed in this article, it is of interest to note that Somali clan genealogies have become charters for the Islamic foundations upon which the society has been built and express in religious terms political prestige and social exclusiveness (Lewis, 1994).

Given the historical relationship of Islam to Somalia, and the importance of the religion to Somali culture, it is of little surprise that young Somalis living in the Toronto diaspora identify themselves as Muslims. What is of particular interest, however, is the degree to which these Somalis associate an Islamic identity with a Somali national identity.

\section{Somali perspectives on Islam and a Somali national identity}

The close coupling of a religious identity with a national one among immigrant and refugee students entering schools in Toronto introduces a complex factor into the traditional relationship between public schooling and national identity construction. This was indeed the case for the Somalis I interviewed. Without exception, when asked about how they identified nationally prior to their migration to Canada, each one of the interviewees stated that they saw themselves nationally as Somali. Further, and of particular relevance to this article, nearly all of the interviewees $(87 \%)$ stated that Islam is a fundamental element of a Somali national identity. This point warrants some attention. Islam is considered to be a significant component of Somali cultural identity (McGown, 1999) and not necessarily a component of a national one. However, when asked to identify the primary characteristics of a Somali national identity, many respondents nonetheless named Islam. It is important to note here that study participants often referred to a 'Somali identity', a 'Somali cultural identity' and a 'Somali national identity' interchangeably and fluidly. As both Mahtani (2002) and 
Radhakrishnan (2003) write, it is in fact not unusual for immigrants in North America to mix ethnic and cultural identifiers within descriptions of a national identity, and this may well have to do with the types of categorizations they encounter upon arriving here (e.g. 'multiculturalism' as a component of national identity within the Canadian context).

When asked to describe how being a Muslim related to a Somali national identity, interviewees most often spoke to the importance of Islam to Somali culture generally, and of the virtual inseparability between culture and religion. Further, several interviewees stated that religion provides a template for behaviors important to Somali culture and identity. Samatar, a 20 -year-old male, stated that religion provides important guidelines in life:

Religion sets our goals. Like [if] we have religion by our side, we won't be on the wrong path. If you follow the religion, you're most likely to succeed in life. So religion is the most important. Like it gets you off of drinking, adultery, stuff like that. So basically if you follow the religion, you're guaranteed paradise.

Nadia, a 21-year-old female, reflected similar sentiments regarding the relationship of Islam to her identity:

BC: How does religion relate to being a Somali?

$\mathrm{N}$ : It's important because religion keeps you safe. It helps you to stay away from certain things, and certain bad things or wrong or whatever. [It] helps to respect each other.... Like for women, you shouldn't shake hands with them (other men), you know? It's dangerous, [because that's] somebody that's not related to you. Religion tells you not to do it. Because of ... this person is not related to you, he's not your husband. He's nothing to do with you, so you shouldn't shake hands with them. So that's one way...

$\mathrm{BC}$ : So these are certain sets of behaviors. And so as you are describing religion to me, it seems like you're describing Somalis to me, and how Somalis behave?

N: Yes.

$\mathrm{BC}$ : Through their religion?

N: Yes.

Here both Samatar and Nadia indicate that religion provides them with a sense of security as well as a set of behavioral guidelines. The importance of this function of religion for new immigrant groups, particularly for those who had heretofore not lived in highly secular environments such as Canada, cannot be diminished. As indicated further below, degrees of religious identity and religious adherence may in fact be closely associated with diasporic conditions.

Expanding this close coupling of Somali identity and Islamic identity, interviewees also stated that it is quite difficult for Somalis not to be Muslims. When asked if it were possible for someone to be a Somali but not be a Muslim, several interviewees stated that this was absolutely not a possibility. Here, interviewees spoke either to the fact that all or nearly all Somalis are Muslims (and so the question is irrelevant), or that the social isolation from the rest of the Somali community that would come about would be so severe as to prevent any chance of deviance. Arale, a 30-year-old male, reflects the former: 
$\mathrm{BC}$ : Is it sort of difficult to separate being a Somali from being a Muslim?

A: Yes, because that's what you learn, that's what everybody is. Like when you're in Somalia, you don't see a Somali who has another religion, like I have never seen one. And that's like ... you know, all of your acquaintances, your classmates, schoolmates, everybody is like this, the same religion. And you don't see ... like you see on TV, when you watch different shows. But not like while you're in Somalia, you [don't] see other nationalities, other different religions. You never saw a Somali with a different religion.

Arale's reference to Somalia proper was not unusual, as many interviewees used traditional Somali society and culture as a reference point when answering the above question. Here Somalia was posited as representing an archetype or ideal of traditional Somali customs and religious practices. Yet other interviewees referred not so much to their homeland as to the existing Somali community in Toronto. Bahdoon, a 25-year-old male, commented on the possibility of a non-Muslim Somali:

It's very difficult. First of all, you would be considered a total outcast by the community. You would not find a place amongst the Somalis, and it would be difficult for you to maintain a Somali identity without [that] religion.

As with Arale, Bahdoon here speaks to a sense of 'inseparability' between Somali and Islamic identity. His reference to the place of religion within the Somali community may indicate the important role that religion plays within Muslim diasporas. In fact, as McGown (1999) writes, the confrontation with highly secularized environments has lead some Muslim immigrant communities to adopt more fundamentalist stances, as traditional religious values are set against what are perceived to be wayward and corrupting influences. ${ }^{11}$

Despite Arale and Bahdoon's fairly strong statements, it is not the case that the interviewees were unanimous on this point. A few stated that people do have choices, and that even if they are born into Somali Muslim families, they can still embrace other religions later in life without 'losing' their identity as Somali. Others spoke to the presence of Christian churches in Somalia, and the fact that some Somalis do convert. Yet overwhelmingly the Somalis interviewed related a Muslim identity very closely with their sense of what constitutes their national identity. It is this type of association that perhaps compels public schools in Canada to take their commitment to multiculturalism seriously. It is also one that can serve as a catalyst for a critical look at how and the degree to which schools in Canada actually advance a multicultural identity. As noted earlier, one way in which the Toronto schools have exercised multiculturalism has been in the provision of prayer spaces for their Muslim student populations. In the narratives featured in the following section, the interviewees spoke to the importance of these provisions, as well as the extent to which the schools made such accommodations.

\section{School policies on religious practices}

Accommodations for religious practices in the Toronto schools were important to the respondents both in principle, and in terms of their own faith practices. With regard 
to the former, interviewees stated that such policies were a matter of rights and individual freedoms. Interviewees also spoke here to a relationship between accommodation policies and the cultivation of a multicultural ethos and a general spirit of tolerance and respect. With regard to the latter, the respondents stated that the school policies were important to them as practicing Muslims, and that they needed such measures to fulfill their personal religious requirements.

While nearly all of the interviewees stated that Islam is a fundamental element of a Somali national identity, not all of them stated that they were practicing Muslims during high school. These interviewees believed that school accommodations for the expression of religion were nonetheless important as a matter of principle, as well as a way of building intercultural understanding. Arale spoke here about the idea of public schools providing facilities for Muslim prayer times:

I think it would be important, I think it would be nice. Because then.... People are scared of what they don't know, but once they know, I don't think they'll be that scared, or they'll get used to it quickly. I don't think you would harm anybody, if like everybody used their own religion. It would just make them closer. If you look at Toronto as a multicultural nation [sic] now, I'm pretty sure in the beginning that they were afraid of people they had never seen before, but once they are used to them, like they would feel comfortable. And I think it (allowing practice of religion in schools) would work the same way.

Arale's association of school prayer policies with a vision of multiculturalism calls attention to the relationship between such measures and the school's broader civic mission. Here Arale appears to view religious accommodations as an extension of general tolerance and respect for religious pluralism. Awarale, an 18-year-old female, made a more direct and personal connection between school policies and her identity:

$\mathrm{BC}$ : Is it important to you that Canadian schools allow you to practice your religion?

A: Of course, because I believe in my religion, and I put religion before anything. And if the school system won't allow me to practice it, I would never go to school.

$\mathrm{BC}$ : Just on that note for a minute, because that is an interesting thing to say ... you wouldn't go to school if the school system...

A: Yeah, because I believe schools are supposed to shape who you are. And if you are going to take the person that I am from me, then I don't need it. That's what I believe.

In comparison to Arale, Awarale takes the role of schooling and religious accommodation one step further by stating that it is in fact a central purpose of the school to 'shape who she is'. In Awarale's case, shaping who she is includes cultivating and sustaining her religious identity. Awarale's comment is of particular interest to the ideas discussed in this article, as she indicates the depth to which Islam is important to her and to her identity. As the passage demonstrates, her faith is so strong that if the schools did not provide such accommodations, she could not see herself as a student in them.

How and the degree to which the Toronto public schools actually provided accommodations for Muslim students is as important to discuss as their reasons for doing so. Here the majority of interviewees stated that the schools overall were accommodating to their needs. However, it must be noted that there is quite a bit of 
variation within this general response. While many schools provided a room for daily and Friday prayers, as well as special lunchtime arrangements during Ramadan, others only made accommodations for one or two of these needs. The schools also varied in terms of how each of the provisions were met. For instance, while many of the interviewees reported that the schools gave them a classroom for their daily prayers and a larger space for Friday sessions, a few respondents reported that their schools allowed Muslim students to attend nearby a mosque. Abukar, an 18-year-old male, recalled his experience:

A: We had a mosque close to us, like a five-minute walk from the school. So we just went, a bunch of us, and then we came back.

BC: I see, so you didn't have a prayer room in the school itself, but you were given time to go to the mosque.

A: Yeah. Because there was a mosque right there, and it would be irrelevant to do the prayers in the school because there was a mosque right there.

Abukar's experience is of particular interest as it signifies the 'surrogate' role that schools play with regard to serving as religious spaces. As the passage demonstrates, Abukar clearly saw the opportunity to pray at a nearby mosque as favorable to praying at the school. At the same time, the passage also demonstrates the range of ways in which schools made accommodations for Muslim students, and indeed the very meaning of 'accommodation' (as spaces within the school to opportunities to leave the school).

While it would seem from the interview accounts that it is relatively easy for Muslim students to perform their religious practices in the Toronto schools, many students have had to organize to get their schools to provide accommodations, particularly through Muslim Student Organizations and other like student groups (Zine, 2000). Four of the Somalis interviewed indicated that their schools were only marginally accommodating to their religious practices. For instance, Alaso, a 25-year-old female, had this to say about one particular teacher:

They had a room for the prayers, yes. And it was very good. Actually, I was very amazed that there was a room for us to go and pray. But the thing is if you had another prayer, sometimes, the other prayer, which is around three o'clock, there is no time, you are in the class. So some of the teachers, I feel like they are upset, you know, 'Alaso, you cannot just go.' And you know.... Like one time-usually I just sit there. Even I don't like to use the bathrooms, so I just to sit there. But one of the teachers especially, I feel like she's not okay with the idea. So I was trying, like if I see that I cannot make it home before the other prayer, I don't want our prayers to come together, you know, they have to be separate. So if I feel like I cannot make it, and I will go and the other prayer will come in, I have to go out. I would just say, I'm sorry, I have to go out. And I tell her, just 10 minutes, because I'm taking off the shoes, 10 minutes and I will finish everything. But if I feel that I can make it home, I don't bother her, I just tell her, you know what? I'm due at home.

Similar to Abukar, Alaso indicates here that she viewed opportunities to pray outside the school (in her case, at home) as favorable to praying inside the school. Further, Alaso's struggle with her teacher over her afternoon prayer time indicates that not only schools but also teachers varied widely with regard to accommodation policies. 
When taken as a whole, what the interviewees indicate is that the accommodations made for them were important, although the manner in which the schools implemented them were far from uniform. It is of particular interest to compare this finding with the narratives featured in the next section. Here respondents were asked to comment on two areas that explicitly reflect the school board's commitment to secularism, namely gender integration in physical education and instruction pertaining to sex and sexuality.

\section{Health and physical education}

The interviewees' experiences with the health and physical education curriculum in the Toronto schools were quite varied. Regarding gender integration in physical education classes, the interviewees reported either accepting and positive experiences, or they expressed some ambivalence. Regarding instruction pertaining to sexuality, their experiences may be generally classified as falling into one of three categories. Here interviewees were accepting and supportive of the curriculum and did not report any parental disapproval, they were accepting and supportive despite parent disapproval, or they were personally ambivalent about the subject in addition to their parents' disapproval.

At the onset of discussing respondents' experiences with gender integration in their high-school gym classes, it is important to note that in at least some of the schools, girls and boys could elect to take same-sex gym classes, thereby avoiding the genderintegrated ones. The following concerns only those experiences of Somali students in mixed-sex classes, as this has been an area of dispute between traditional Muslim groups and the Toronto schools.

As noted above, respondents' experiences pertaining to physical education were generally either positive or ambivalent. Regarding the former, which accounts for a little over half of the group, interviewees stated that they were comfortable with the class in the way it was organized and that they liked or enjoyed the class overall. Perhaps not surprisingly, the young men interviewed generally reported fewer difficulties with the concept of mixed-sex gym classes. However, girls too were comfortable with the class, as Adey, a 22-year-old female, indicated:

BC: Were your gym activities co-ed, or did they keep the boys and girls separate?

A: Sometimes it would be co-ed, sometimes they keep them separate...

$\mathrm{BC}$ : Some of the activities that you were in were co-ed?

A: Yes.

BC: And in school, how did you feel about that, I mean...

A: Well I was very comfortable because I love sports, so that was not going to matter for me at all.

BC: I see. And it didn't produce any kind of conflict for you as a Somali to be physically engaging with other boys in the physical education class?

A: Ah, no not really.

In this passage Adey indicates that her 'love of sports' trumped any potential difficulties she may have had with the concept of mixed-sex classes. Her exercise of personal 
choice and freedom in this matter is an important component of the types of identity processes that the interviewees engaged in while at school. Magol, also a 22-year-old female, reflected similar sentiments:

BC: Were your gym classes co-ed, or were the boys and girls separate?

M: $\quad$ It was co-ed for the first year. And the second, Grade 10, [it] was separate.

BC: And how was that experience for you as a Somali, as a Somali woman in particular?

M: That didn't really bother me back in Grade 9. I wasn't uncomfortable with boys being there, you know. Because we had our own separate change rooms and we just see each other in the hall, or I'm sorry, in the gym class, but that was it really.

As with Adey, Magol here reflects an open attitude towards mixed-sex classes. She is agreeable with the standard provisions that the school employed for splitting the sexes (separate change rooms) and does not mention any religious or cultural conflicts with the rest of the course format. A smaller number of the interviewees did, however, indicate some personal ambivalence about mixed-sex gym classes. Here the interviewees stated that they took physical education courses because the classes were required, but that some elements of the course (particularly gender integration) conflicted with their own religious or cultural values. This response was not limited to females. Othman, a 25-year-old male, had this to report:

O: It (mixed-sex classes) didn't bother me. Except when we learned to go swimming, then we got difficulties [laughs]. I hated swimming, I couldn't swim and ... you gotta take your clothes off (appear in swimsuits) in front of the females, like [it was] uncomfortable.

BC: Well, that's what I'm getting at.

O: $\quad$ Yah-

BC: $\quad .$. is whether it was uncomfortable because of possibly the cultural differences...

O: Yah.

BC: $\quad$...of having girls and boys mixed.

O: Yah. Because also we have Ramadan during those times.

BC: Right.

O: $\quad$ So it's strange like to see. Like, I don't mind seeing a female wearing shorts, but like sometimes they would wear skimpy outfits. And then [the out fits are] relatively small because it is gym after all. But it wasn't a crazy shock. It was just like I was taken aback, I was like okay, you know. And you're not supposed to look and stuff like that.

BC: Right.

In this passage Othman indicates two major reasons for his discomfort with the swimming instruction. First, he was unaccustomed both to appearing before women in only his swim trunks and to seeing women in what he deemed to be quite compromising swimsuits ('skimpy outfits'). Second, he felt that the environment surrounding the instruction was a front to his religious principles, particularly in light of Ramadan, a period of acute observance.

Other respondents who had conflicting experiences with gender-integrated gym classes also made direct references to Islam in their comments. One female stated that she did not think it was appropriate, for religious reasons, to have boys and girls mixing together in gym. Another stated that, while she herself had no real problems 
with gender integration, her mother did, which resulted in some mixed feelings on her part. The issue of mixed-sex gym classes was not nearly as contentious nor complex, however, as the topic of sexuality.

The majority of the interviewees conveyed a generally accepting and supportive attitude toward their high-school instruction on sex and sexuality. Further, a little less than half of these interviewees did not report any strong parental disapproval of the subject being taught in the school, although some did speak of a general tendency for sex to be a 'taboo' subject within traditional Somali society and communities. The interviewees who were most open and accepting of the subject believed that it is an appropriate topic to teach in the public schools and, further, that it is an important topic to teach because of the behaviors of contemporary youth in Canada. Some also made reference to contexts outside of Canada, most commonly Somalia, as informing their present beliefs. Omar, a 19-year-old male, spoke to several of these points:

BC: So overall, do you think it's appropriate for public schools to teach sex education?

O: Yeah. Basically, I believe that if you learn sex education, like for example in Somalia they probably think it's wrong to learn sex education. But if you learn it-and in Ethiopia as well — but if you learn it from the beginning, like the more education you have on it, it could stop things. Like we'll be more aware of AIDS and things like that. But people don't really think of that. They think it's wrong to have. They think that it's going to make kids want to go and have sex. But in actuality that thing, that's still going to happen. But if we're educated on AIDS and how to prevent it and different STDs, it would maybe help with that. I think that's going to be hard to instill in the people, very hard actually.

$\mathrm{BC}$ : 'The people' meaning the first generation, the older generation?

O: Yeah.

In this passage Omar compares what he believes to be the attitude toward sex education in Somalia and Ethiopia with what he sees as an appropriate response to present realities in Canada. He aligns the former with what might be termed a 'traditional' stance on the topic, and the latter with school-based instruction on sex and sexually transmitted diseases. His use of the terms 'people' and 'the people' to refer to those within the Somali community speaks to the degree to which traditional views toward sex education permeate the diaspora.

Omar's reference to more traditional views pertaining to sex within Somali society was in fact a common component in many of the interviewees' responses. This was particularly the case among respondents who supported the teaching of the topic despite the strong concerns of their parents. In these cases the interviewees reflected many of the sentiments as the group above. However, they also made direct mention of parental disapproval. One interviewee, a 20-year-old male named Guleed, spoke of parental efforts to actually remove their children from the class:

G: It (instruction pertaining to sex) was part of gym class. I always remember that part of the semester. For about two weeks we did health studies, and we talked about everything about health, from bones to actual sex. And I remember this because in Somalia, in Islam, sex is not something you talk about in public. Sex is like, you know, it's there, and then when you get to a certain age, you will be educated about it, and then that's it. You don't talk about it in public. And now it was in the open, 
and there were people that were coming in that had these big wooden things and they had condoms and they were saying protect yourself. And I remember there were a lot of Somali students' parents, and even other students' parents that came. And they really didn't like what was going on, because it looked like sex was kind of encouraged-sex is going to happen, [so] protect yourself.

BC: $\quad$ Right. Kind of like an inevitable....

G: And in Islam, sex is not something that comes into your life until marriage.

BC: So the parents actually came to the school to complain?

G: Yes, the parents came. And so I remember after that, two Somali students, two Somali girls, were not a part of that health class for two weeks after that because their parents complained about it. There was also like an Indian girl and another boy, there were like five of them altogether I guess who didn't come.

Similar to Omar, Guleed makes a comparison here between practices in Somalia as guided by Islamic principles ('in Somalia, in Islam') and practices in Canada. Importantly, he refers to schooling as a part of the larger public domain and contrasts this with a norm of not talking about sex 'in public'. His account of parental intervention to remove students from sex education speaks to the lengths that some members of the Somali diaspora (and other immigrant communities) will go to preserve religious beliefs and practices. Further, it underscores the sometimes strong influence that parents have on the school experiences of new immigrant youth.

Guleed further reports that, while his mother strongly disliked the fact that the topic was being taught in his school, she nonetheless deferred to his judgment. His personal view of the class reflects the intergenerational differences so often mentioned among the respondents:

BC: And how did it sit with you personally? I mean, did you feel as though this is the proper place to teach sex education?

G: Yeah, I understood why the teachers did it. I understood that a lot of kids engaged in it, you know, and that it was only right to at least teach them about it if they're going to do it. You can't lie to yourself and force yourself [into believing] that these kids are not doing it. So, they are just taking precautions. They said, 'Here, if it's going to happen, let's just teach them about it for two weeks.' You know, it wasn't a whole course, it was just kind of a unit.

BC: And you understood that?

G: I understood that. I learned it, and I think that was helpful, to be honest. So whenever I wish to engage in it, I'll know what to do, you know, I will have enough background for it.

Again, similar to Omar, Guleed indicates here that sex education in Canada is an appropriate as well as 'helpful' response to the realities of teen sex that he has come to understand. As demonstrated further below, interviewees often associated this particular orientation to sex education with the 'Canadian' view, and contrasted this with their sense of a 'Somali' view.

There was a small number of interviewees who had much more personally ambivalent or oppositional orientations toward sex and sexuality instruction. Respondents in this group reported that they took this instruction because it was required, but stated that it, or some elements of it, conflicted with their religion. In one case, a male had attempted to get out of the class but could not do so. Similar to the other 
interviewees, this group made reference to Islam and traditional Somali culture when constructing their responses. Awa, a 20-year-old female, perhaps best captured the identity struggles represented in this group:

A: That [sex and sexuality instruction] was different, because for us [Somalis], we're not exposed to sex, and you're never supposed to mention that in front of anybody, except like your closest friends. You never talked about it to your parents or relatives. It was like a taboo, you're not supposed to talk about that. So what do we do? We're sitting there in the grade 9 classroom. But before grade 9, I was exposed to it, like in grade 6 we talked about it. But I never came home and told them [parents/elders].

BC: So you didn't? So you didn't come home and tell your parents, guess what we studied in school today?

A: Nope.

BC: Now what were your own personal views on it? Did you think that this was the correct thing for schools to do?

A: I think it was a good thing to do, because we all need to know about our body parts you know. For health issues, it's important for us to learn. And I don't know what are the reasons behind our not talking about it. I think we should talk about it, it's important that we talk about it, it's all about our body and what you know doesn't hurt. So you know these issues. Like for example, pregnancy, you see what causes it, how can you prevent it, and all of those things. But at the same time, you look at it and there's something in me that tells me maybe it's not right, maybe they're teaching us you know, it's okay to go and have sex, because now we have protection. So it's like, sort of like a collision between two cultures. You have the Canadian view, the Canadian view, you know, 'Yeah, it's good, you should learn about it.' But then, it's like, well maybe it's not that great because it's a way of promoting sex. I know it's not right, but what about like general people? Somebody my age, and she is sitting in that classroom thinking maybe my mother is not there this afternoon, and we'll have sex. And I don't want to get pregnant, why not use protection? That sort of thing, there is a mixture of both views.

Awa's account speaks to a critical issue embedded in this article, and that concerns a clash of generations and cultures. Her orientation to this particular school practice is two-fold. On the one hand, she identifies with what she calls 'the Canadian view', and displays an instrumental orientation to the subject (i.e. maintaining one's health, uses of birth control). On the other hand, she clearly feels connected to what she depicts as traditional Somali cultural views. In the end, she is unsure whether the classes are indeed promoting sex, or whether they are simply providing instruction about sex. Yet Awa's ambivalence does not signify that these Somalis are, as a whole, fundamentally confused and culturally disoriented. Indeed, they may be at the forefront of creating new identity constructions.

\section{Identity vanguards}

When taken as a whole, interviewees' identifications with Islam and their public school experiences with regard to policies on religious accommodation as well as health and physical education exist on a continuum in terms of consistency of views with the Muslim voices depicted by Shaheen Azmi (2001). Certainly, the 
close coupling of a Muslim identity with a national or cultural one would appear to accord quite closely with the position of the Muslim groups Azmi writes about. However, with respect to school policies and practices, it is interesting to note that the 'more secular' the policies, the greater the divergence the interviewees had from the voices of these groups. That is, while the interviewees were nearly unanimous in their support for school-based prayer accommodations - a position advocated by traditional Muslim groups - they were at least ambivalent about if not out rightly supportive of gender-integrated physical education classes and, more so, instruction pertaining to healthy sexuality. This is to say, then, that whereas the struggles that Azmi depicts centered on advancing policies most favorable to Islamic practices and removing policies most challenging, the interviewees featured here were far more accepting of both multicultural as well as secular school policies.

The above provides some insights into the types of identity processes that the interviewees engaged in while at school. Chief among these is that the variety of their experiences with and perspectives on the school policies covered here (from rejection to ambivalence to acceptance) speaks strongly against any notions of absolutism or essentialism in terms of their collective identity. Thus, there is not one Somali Muslim identity that may be said to represent all of the interviewees. Rather, the picture that the narratives display represents a number of individual biographies, each representative of a young person forging ahead and constructing an identity that works for them. What is common across the narratives is: (1) a sense of individual autonomy and choice about what to accept or reject within the school (notwithstanding pressures exerted by parents or elders); and (2) a sense of fluidity within their identities. As an example of the former, interviewees such as Adey stressed that her own love for sport trumped any potential cultural conflicts that might have arisen having to do with mixed-gender environments. As an example of the latter, interviewees such as Awa spoke to embracing both 'Somali' and 'Canadian' views with respect to sex and sexuality instruction.

Papastergiadis' (1998) notion of diasporic identities as forming in relation to specific social, cultural and historical contexts rather than being natural, exclusive or fixed, as well as Hall's (1999) conception of diasporic identities as being 'emergent', situational, and highly sensitive to context capture well the foregoing illustrations. Further, and perhaps more pointedly, the identity processes featured in the narratives 'disrupt' the binaries through which school policies and practices are typically problematized. This has much importance for our thinking about the nature and role of public schooling with new immigrant groups.

Schools with new immigrant communities such as Somalis may be thought of as 'diaspora spaces'. As sites of cultural becoming and (re)identification for diasporic peoples, they are places where the permitted and the prohibited are continuously interrogated (Yon, 2000). In the context of public schooling in Toronto, the permitted versus prohibited dichotomy may be framed within the multicultural versus secular liberal divide. Yet, whereas the dichotomy presents itself as a perpetual challenge for policy makers, scholars and activists of the type written 
about by Azmi, for the interviewees it appears to be just part and parcel of the terrain within which they strategically maneuvered in their construction of a meaningful identity. In other words, the question is not so much about the degree to which school policies and practices are countervailing within the secular versus non-secular divide, as the degree to which this dichotomy mattered to the students.

The foregoing is not to say that the multicultural-secular liberal division is unimportant in terms of interrogating public school policies and practices in Canada. Indeed, the dualism is likely to continue to represent a focal point for cultural struggles between varying immigrant groups and public school boards. More so, in the post-9/11 era of state security, and attendant anxiety over immigrant groups (particularly Muslim), school policies and practices that mirror the 'state of the state' should be closely monitored and scrutinized for new forms of racism and social exclusion, including the areas of school-community relations as well as teacher professional development. Along these lines, educators should be continuously mindful of how and where multicultural curricula may essentialize student identities and hence thwart understanding of the complexities and multiplicities through which students may actually understand themselves. The foregoing is to say then that new immigrant students hold out the promise of forging creative and heretofore unforeseen subject positions that call into serious question the 'identity categories' within which they are so often viewed. Hence, it is possible for a student to identify as a Muslim, make use of accommodations provided in the school for daily prayer and participate in and benefit from gender-integrated physical education classes as well as instruction pertaining to sex and sexuality. Is their sense of nationality 'compromised' by such a position? Their religion?

\section{Conclusion}

While this article has not attempted to answer how Somali immigrants who graduate from Toronto public high schools identify nationally post-graduation, it has examined one important context through which these identity constructions are taking shape. The Somalis interviewed for this study entered the Toronto schools with strong identifications as Muslims and closely associated their religious affiliations with a Somali national identity. The presence of this very complex dynamic provides an important opportunity for examining how the schools have both supported and challenged these identities. The negotiation and renegotiation processes that Somali students have engaged in with the Toronto schools regarding these practices calls attention to particular forums where national identity plays an important role. The foregoing case demonstrates that far from falling 'victim' to a secular-religious divide, the respondents featured here were very much actors and co-creators in their identification processes. Correspondingly, the case invites more research into the meaning of multiculturalism from the viewpoint of recent immigrants themselves, which is still very much fertile terrain. 


\section{Notes}

1. Midaynta Community Services had previously operated under the name Midaynta Association of Somali Service Agencies. The organization changed its name in 2005.

2. A note regarding the specific school boards in operation during the period that the interviewees attended high school (1995-2005). In January 1998, the Ontario Ministry of Education and Training moved to amalgamate Ontario's then 129 school boards into 60 new Englishlanguage boards and 12 new French-language boards. The amalgamation was part of a fundamental realignment of taxation and spending between the province of Ontario and its municipal governments brought on by the 1995-elected Ontario Progressive Conservative Party. This realignment also saw the amalgamation of the five cities and one borough that had constituted the Municipality of Metropolitan Toronto, and subsequently the merging of the six previous boards into the single Toronto District School Board (Basu, 2004). As these changes pertain to the article, four of the respondents attended high schools that merged into the larger board after they had already graduated.

3. Public schooling in Ontario is divided into elementary (Junior Kindergarten to Grade 8) and secondary (Grades 9-12) levels. To earn an Ontario Secondary School Diploma, high-school students must earn a minimum of 30 credits ( 18 compulsory and 12 optional). They must also complete 40 hours of community involvement activities. Finally, they must pass a provincial secondary school literacy test (Ontario Ministry of Education, 2005).

4. It should be noted that not all groups were believed to be capable of assimilating, leading to segregated schools for such populations as African-Canadians as well as Asian immigrants.

5. Regarding the Canadian context, see Bissoondath (1994). Also, see D'Souza (1992), Ravitch (1992) and Schlesinger (1991, 1992).

6. It is important to note that Azmi's (2001) study specifically covers the resistance of the Sunni and Ithna-Ashari Shiite communities in Toronto, and does not therefore speak for all Muslim groups. By extension, the article should not be interpreted as applying to all Somali Muslims.

7. Sanjakdar (2004) notes that discussion, teaching and learning about sex, sexuality and sexual health are not opposed in Islam. Rather, she asserts that from a Muslim point of view, such instruction must be done within a greater framework of Islamic teachings and principles.

8. With regard to the provision of space for Muslim prayers in the Toronto public schools, Zine (2000) has documented the struggles that many Muslim students have had with school administrative staff to make such provisions actually possible.

9. Also see Scott (2001).

10. Hijra means to migrate, withdraw or abandon. In Islam, the hijra refers to the exodus of Muhammad and his followers from Mecca to Medina in $\mathrm{AD}$ 622, which dates the beginning of the Islamic calendar.

11. It is of interest to note that, historically, the country of Somalia has not been home to Islamic fundamentalism and Somalis (nearly all Sunni Muslims) have not in the past been particularly strict with regard to their application of Islamic laws (Menkhaus, 2002).

\section{References}

Azmi, S. (2001) Muslim educational institutions in Toronto, Canada, fournal of Muslim Minority Affairs, 21, 259-272.

Basu, R. (2004) The rationalization of neoliberalism in Ontario's public education system, 1995-2000, Geoforum, 35, 621-634.

Bissoondath, N. (1994) Selling illusions: the cult of multiculturalism (Toronto, Penguin).

Boyatzis, R. E. (1998) Transforming qualitative information: thematic analysis and code development (Thousand Oaks, CA, Sage). 
Braungart, R. G. \& Braungart, M. M. (1997) Political socialization and education, in: L. Saha (Ed.) International encyclopedia of the sociology of education (London, Pergamon), 521-527.

D'Souza, D. (1992) Illiberal education: the politics of race and sex on campus (New York, Vintage).

Epstein, E. H. \& McGinn, N. F. (2000) Introduction, in: E. Epstein \& N. McGinn (Eds) Comparative perspectives on the role of education in democratization, part II: socialization, identity, and the politics of control (New York, Peter Lang), 1-15.

Feinberg, W. (1998) Common schools / uncommon identities: national unity and cultural difference (New Haven, MA, Yale University Press).

Froese, D. (2003) Roots and identity. Available at: http://www.uask.ca/education (accessed 22 September 2003).

Hall, S. (1999) The global, the local, and the return of ethnicity, in: C. Lemert (Ed.) Social theory: the multicultural and classic readings (Bolder, CO, Westview), 626-633.

Hebert, Y. (2001) Identity, diversity, and education: a critical review of the literature, Canadian Ethnic Studies, 33, 155-186.

Immen, W. (2000, December 26) Somalis pitch in for mutual aid; new beginnings in Canada mean low-paid jobs, unfamiliar surroundings for refugees from war-torn East Africa, The Globe and Mail, A22.

Joshee, R. (2003) Citizenship and multicultural education in Canada: from assimilation to social cohesion, in: J. Banks (Ed.) Diversity and citizenship education: global perspectives (San Fransicso, CA, Jossey-Bass), 127-156.

Kusow, A. (1998) Migration and identity processes among Somali immigrants in Canada. Dissertation, Wayne State University, Michigan (Ann Arbor, MI, UMI).

Lewis, I. M. (1994) Blood and bone: the call of kinship in Somali society (Lawrenceville, NJ, Red Sea Press).

Mahtani, M. (2002) Interrogating the hyphen-nation: Canadian multicultural policy and 'mixed race' identities, Working Paper No. 20 (Toronto, Joint Centre for Excellence for Research on Immigration and Settlement).

May, S. (1999) Critical multiculturalism and cultural difference: avoiding essentialism, in: S. May (Ed.) Critical multiculturalism: rethinking multicultural and antiracist education (London, Falmer), 11-41.

Mazurek, K. \& Kach, N. (1990) Multicultural ism, society and education, in: E. B. Titley (Ed.) Canadian education: historical themes and contemporary issues, (Calgary, Canada, Detselig), 133-160.

McGown, R. (1999) Muslims in the diaspora: the Somali communities of London and Toronto (Toronto, University of Toronto Press).

Menkhaus, K. (2002) Political Islam in Somalia, Middle East Policy, 9: 109-124.

Midaynta Association of Somali Service Agencies (2003) Somali community gang intervention and exit strategy program. Program material (Toronto, Midaynta Association).

Ontario Ministry of Education (1999) Health and physical education curriculum, grades 9 and 10 (Ottawa, Ontario Ministry of Education).

Ontario Ministry of Education (2005) Ontario secondary schools grades 9 to 12 program and diploma requirements. Policy document (Ottawa, Ontario Ministry of Education).

Palmer, H. (1993) Mosaic versus melting pot? Immigration and ethnicity in Canada and the United States, in: D. Taras, B. Rasporich \& E. Mandel (Eds) A passion for identity: an introduction to Canadian studies (2nd edn) (Nelson Scarborough).

Papastergiadis, N. (1998) Dialogues in the diasporas: essays and conversations on cultural identity (London, Rivers Oram).

Radhakrishnan, R. (2003) Ethnicity in the age of diaspora, in: S. J. Braziel, \& A. Mannur (Eds) Theorizing diaspora (Malden, Blackwell).

Ravitch, D. (1992) Diversity in education, Dialogue, 95, 39-47.

Rosa, B. \& Dick, H. (2000) Public schooling in English Canada: addressing differences in the context of globalization, Canadian Ethnic Studies, 1, 38-54. 
Sanjakdar, F. (2004) Developing an appropriate sexual health education curriculum framework for Muslim students, in: B. Van Driel (Ed.) Confronting Islamophobia in educational practice (Stoke-on-Trent, Trentham), 143-162.

Schlesinger, A. (1991) The disuniting of America: what we all stand to lose if multicultural education take the wrong approach, American Educator, 15, 14-33.

Schlesinger, A. (1992) The disuniting of America: reflections on a multicultural society (New York, W. W. Norton).

Scott, J. (2001) A study of the settlement experiences of Enitrean and Somali parents in Toronto. Report (Toronto, Praxis Research and Training).

Toronto Board of Education (1992) Report on the religious needs of Muslim students in Toronto Board of Education schools (Toronto, Equal Opportunity Office and Equity Studies Centre, Toronto Board of Education).

Waters, T. \& Leblanc, K. (2005) Refugees and education: mass public schooling without a nationstate, Comparative Education Reviez, 49, 129-147.

Yon, D. (2000) Elusive culture: schooling, race, and identity in global times (New York, State University of New York Press).

Zine, J. (2000) Redefining resistance: towards an Islamic subculture in schools, Race Ethnicity and Education, 3, 293-316. 